\title{
Predominance of the c.648G > T G6PC gene mutation and late complications in Korean patients with glycogen storage disease type la
}

\author{
Yoo-Mi Kim', Jin-Ho Choi ${ }^{2}$, Beom-Hee Lee ${ }^{2,3}$, Gu-Hwan Kim³, Kyung-Mo Kim² and Han-Wook Yoo ${ }^{2,3^{*}}$ (I)
}

\begin{abstract}
Background: Glycogen storage disease (GSD) la, caused by mutations in the glucose-6-phosphatase (G6PC) gene, is characterized by hepatomegaly, hypoglycemia, lactic acidosis, dyslipidemia, and hyperuricemia. This study aimed to investigate clinical and molecular features and late complications in Korean patients with GSD la.

Results: Fifty-four Korean patients (33 males and 21 females) from 47 unrelated families, who were diagnosed with GSD la, based on genetic and biochemical data, between 1999 and 2017, were included in this study. The median age at diagnosis was 3.9 years (range: 5 months to 42 years), and the follow-up period was $8.0 \pm 6.8$ years. Most patients presented with hepatomegaly during infancy, but hypoglycemic symptoms were not predominant. Genetic analysis showed that all the patients had at least one c.648G > T allele. Homozygous c.648G > T mutations in the G6PC gene were identified in 34 families (72.3\%), and compound heterozygotes with c.648G > T were found in the other families. The allele frequency of c.648G > T was 86.2\% (81/94), and p.F51S, p.R83H, p.G122D, p.Y128*, p.G222R, and p.T255A were identified. Of 26 adult patients, 14 had multiple hepatic adenomas, and two were diagnosed with hepatocellular carcinoma. Thirteen patients showed renal complications, and seven patients presented gout, despite preventive allopurinol treatment. Twelve patients had osteoporosis, and two patients had pulmonary hypertension. The final heights were $157.9 \mathrm{~cm}$ (standard deviation score: -3.1 ) in males and $157.8 \mathrm{~cm}$ (standard deviation score: - 0.6) in females.
\end{abstract}

Conclusion: In our Korean patients with GSD la, the most common mutation in the G6PC gene was c.648G > T, suggesting a founder effect. Because of only mild hypoglycemia, the patients tended to be diagnosed late. Thus, adult patients with GSD la eventually developed diverse and serious complications, which indicates a need for careful monitoring and proper management of this disease.

Keywords: Glycogen storage disease, G6PC, Adult, Complication

\section{Background}

Glycogen storage disease (GSD) type Ia (OMIM \#232200) is a rare inborn metabolic disorder, caused by glucose-6phosphatase (G6PC) deficiency, and the overall incidence is considered to be one in $100,000[1,2]$. This disease leads to defects in glycogenolysis and gluconeogenesis,

\footnotetext{
* Correspondence: hwyoo@amc.seoul.kr

${ }^{2}$ Department of Pediatrics, Asan Medical Center Children's Hospital,

University of Ulsan, College of Medicine, Seoul, Korea

${ }^{3}$ Department of Medical Genetics, Asan Medical Center Children's Hospital,

University of Ulsan, College of Medicine, Seoul, Korea

Full list of author information is available at the end of the article
}

resulting in the inhibition of glucose production and accumulation of glycogen and fat in the liver, kidney, and intestinal mucosa $[2,3]$. The clinical manifestations include hepatomegaly, hypoglycemia, lactic acidosis, hypertriglyceridemia, and hyperuricemia, which are usually manifested in the infantile period. In addition, hepatocellular adenoma and renal dysfunction are frequent late complications [1-3]. Delayed diagnosis and inappropriate therapy lead to many complications, such as growth failure, osteoporosis, refractory gout, renal failure, hepatocellular carcinoma (HCC), and pulmonary hypertension [4-6]. The G6PC

(c) The Author(s). 2020 Open Access This article is distributed under the terms of the Creative Commons Attribution 4.0 International License (http://creativecommons.org/licenses/by/4.0/), which permits unrestricted use, distribution, and 
gene, encoding G6PC, has been mapped to chromosome $17 q 21$ [7], and 110 mutations in G6PC have been reported until now. Among them, 70 missense mutations, 14 nonsense mutations, 21 insertions/deletions, and five splicing mutations have been reported (Human Gene Mutation Database: http://www.hgmd.cf.ac.uk). c.648G $>\mathrm{T}$ is considered a common mutation in Korean and Japanese patients with GSD Ia $[8,9]$; however, there have only been a few reports on clinical characteristics and long-term outcomes of c.648G > T-carrying patients with GSD Ia in a large cohort.

Therefore, this study aimed to investigate clinical and molecular features and late complications in Korean patients with GSD Ia, with a particular focus on c.648G > $\mathrm{T}$-carrying patients.

\section{Results}

\section{Clinical characteristics and biochemical data}

The mean and median age at diagnosis were $9.1 \pm$ 10.7 and 3.9 years (range: 5 months to 42 years), respectively, and the follow-up period was $8.0 \pm 6.8$ years (Table 1 and Additional file 1: Table S1). Most patients presented with hepatomegaly during infancy and early childhood, whereas nine patients (16.7\%) first showed symptoms after 20 years of age. Among late-diagnosed patients, four patients presented with gout, and one patient had dyspnea due to pulmonary hypertension. Three patients visited the hospital for a hepatic mass or hepatomegaly, and one patient had a long-bone fracture and osteoporosis (Table 2). The mean serum glucose level at diagnosis was $79.4 \pm 27.7$ $\mathrm{mg} / \mathrm{dL}$. The serum lactic acid and uric acid levels at diagnosis were $26.1 \pm 31.9 \mathrm{mmol} / \mathrm{L}$ and $8.0 \pm 2.7 \mathrm{mg} /$ $\mathrm{dL}$, respectively. The serum cholesterol $(230.4 \pm 86.2$ $\mathrm{mg} / \mathrm{dL})$ and triglyceride $(649.7 \pm 467.1 \mathrm{mg} / \mathrm{dL})$ levels were also high (Table 1).

The height standard deviation score (SDS) at diagnosis was $-2.3 \pm 2.0$ (females: $-1.5 \pm 1.9$; males: $2.8 \pm 2.1$ ). The midparental height SDS was $-0.2 \pm 0.7$ (females: $-0.4 \pm 0.5$; males: $-0.01 \pm 0.8$ ). We divided the two groups into early diagnosed patients (age at diagnosis < 3 years) and delayed diagnosed patients (age at diagnosis $\geq 3$ years). At the time of diagnosis, early diagnosed patients were significantly taller than delayed diagnosed patients $(-1.2 \pm 1.8$ SDS vs. $-3.0 \pm$ 2.0 SDS, $p<0.05)$ and had lower lactic acid levels $(8.3 \pm 7.6 \mathrm{mmol} / \mathrm{L}$ vs. $29.2 \pm 34.1 \mathrm{mmol} / \mathrm{L}, \quad p<0.05)$. Uncooked cornstarch and allopurinol were prescribed for all patients. The mean dose of uncooked corn starch was $7.2 \pm 2.4 \mathrm{~g} / \mathrm{kg} /$ day. Twenty patients required

Table 1 Demographic and clinical characteristics and genotypes of 54 patients with GSD la

\begin{tabular}{|c|c|}
\hline Characteristic & Total patients $(n=54)$ \\
\hline Males/Females & $33: 21$ \\
\hline Age at diagnosis & $9.1 \pm 10.7$ (5 months to 42 years) \\
\hline Age at last visit & $16.8 \pm 13.1$ (13 months to 43 years) \\
\hline Familial cases & 7/47 families (14.9\%) \\
\hline \multicolumn{2}{|l|}{ Laboratory findings and height at diagnosis } \\
\hline Random glucose (mg/dL, RR: 70-120) & $79.4 \pm 27.7$ \\
\hline Lactate (mmol/L, RR: 0.8-2.1) & $26.1 \pm 31.9$ \\
\hline Uric acid (mg/dL, RR: 3.2-7.4) & $8.0 \pm 2.7$ \\
\hline Hemoglobin (mg/dL, RR: 13-16) & $10.8 \pm 2.0$ \\
\hline Cholesterol (mg/dL, RR: 125-220) & $230.4 \pm 86.2$ \\
\hline Triglycerides (mg/dL, RR: 45-150) & $649.7 \pm 467.1$ \\
\hline Height (standard deviation score) & $-2.26 \pm 2.03$ \\
\hline \multicolumn{2}{|l|}{ Genotype } \\
\hline c.648G $>\mathrm{T}+\mathrm{c} .648 \mathrm{G}>\mathrm{T}$ & 34/47 families (72.3\%) \\
\hline c.648G > T + p.G122D & 4/47 families (8.5\%) \\
\hline c.648G > T + p.G222R & 3/47 families (6.4\%) \\
\hline c.648G > T + p.Y128* & 2/47 families (4.3\%) \\
\hline c.648G > T + p.S326P & 1/47 families (2.1\%) \\
\hline c.648G > T + p.T255A & 1/47 families (2.1\%) \\
\hline c.648G > T + p.F51S & 1/47 families (2.1\%) \\
\hline c.648G $>\mathrm{T}+\mathrm{p} . \mathrm{R} 83 \mathrm{H}$ & 1/47 families $(2.1 \%)$ \\
\hline
\end{tabular}


Table 2 Long-term complications in 26 adult patients with glycogen storage disease type la

\begin{tabular}{|c|c|c|c|c|c|c|c|c|c|c|c|c|c|c|c|c|}
\hline Subject & Sex & $\begin{array}{l}\text { Recent age } \\
\text { (years) }\end{array}$ & $\begin{array}{l}\text { Age at diagnosis } \\
\text { (years) }\end{array}$ & $\begin{array}{l}\text { Presenting } \\
\text { symptoms }\end{array}$ & Allele 1 & Allele 2 & $\mathrm{DL}$ & $\mathrm{HA}$ & $\mathrm{OP}$ & $\mathrm{RC}$ & $\begin{array}{l}\text { SS } \\
\text { (SDS) }\end{array}$ & AN & $\mathrm{DP}$ & GT & $\mathrm{PH}$ & $\mathrm{HCC}$ \\
\hline $1^{a}$ & $\mathrm{~F}$ & 47.8 & 29.2 & $\mathrm{FS}, \mathrm{OP}$ & c.648G $>\mathrm{T}$ & c.648G $>\mathrm{T}$ & + & - & + & - & -1.0 & - & - & + & - & - \\
\hline 2 & M & 43 & 42 & $\mathrm{HM}, \mathrm{GT}$ & c.648G > T & c.648G > T & + & + & - & + & -2.9 & + & - & + & - & + \\
\hline 3 & M & 43 & 23 & Hp, GT & c. $648 \mathrm{G}>\mathrm{T}$ & c. $648 \mathrm{G}>\mathrm{T}$ & + & - & - & + & -2.7 & + & - & + & - & - \\
\hline $4^{a}$ & M & 41 (Ex) & 31 & $\mathrm{Hp}, \mathrm{Ds}$ & c. $648 \mathrm{G}>\mathrm{T}$ & c.648G $>\mathrm{T}$ & + & + & - & - & -3.3 & - & - & + & + & - \\
\hline $5^{b}$ & $\mathrm{~F}$ & 40 & 36 & GT, FS & c. $648 \mathrm{G}>\mathrm{T}$ & c. $648 \mathrm{G}>\mathrm{T}$ & + & - & - & - & 0.8 & - & + & + & - & - \\
\hline $6^{b}$ & F & 37 & 33 & GT & c.648G > T & c.648G > T & + & + & + & + & -3.4 & + & + & + & - & - \\
\hline 7 & M & 36 & 26 & $\mathrm{Hp}$ & c. $648 \mathrm{G}>\mathrm{T}$ & c. $648 \mathrm{G}>\mathrm{T}$ & + & + & + & + & -3.7 & + & + & + & - & - \\
\hline $8^{c}$ & M & 34.1 & 13.7 & $\mathrm{Hp}, \mathrm{GR}$ & c. $648 \mathrm{G}>\mathrm{T}$ & c. $648 \mathrm{G}>\mathrm{T}$ & + & - & - & - & -1.7 & + & - & - & - & - \\
\hline 9 & M & 28.7 & 14.8 & $\mathrm{Hp}, \mathrm{GR}$ & c. $648 \mathrm{G}>\mathrm{T}$ & c. $648 \mathrm{G}>\mathrm{T}$ & + & + & + & + & -5.0 & + & - & - & - & - \\
\hline $10^{d}$ & $F$ & 26.2 & 8.9 & $\mathrm{Hp}, \mathrm{GR}$ & c. $648 \mathrm{G}>\mathrm{T}$ & c. $648 \mathrm{G}>\mathrm{T}$ & + & + & + & - & -2.2 & - & - & - & - & - \\
\hline 11 & $\mathrm{~F}$ & 24.1 & 4.3 & $H p, G R$ & c. $648 \mathrm{G}>\mathrm{T}$ & $c .648 \mathrm{G}>\mathrm{T}$ & + & + & + & + & -1.2 & + & + & - & - & - \\
\hline $12^{d}$ & M & 21.8 & 5.8 & $\mathrm{Hp}, \mathrm{GR}$ & c. $648 \mathrm{G}>\mathrm{T}$ & c. $648 \mathrm{G}>\mathrm{T}$ & + & - & + & + & -2.8 & - & - & - & - & - \\
\hline 13 & M & 21.4 & 20.8 & $\mathrm{Hp}, \mathrm{GR}$ & c.648G > T & c.648G > T & + & + & + & + & -7.5 & - & + & - & - & - \\
\hline $14^{c}$ & F & 20.8 & 1.8 & FS & c. $648 \mathrm{G}>\mathrm{T}$ & c. $648 \mathrm{G}>\mathrm{T}$ & + & + & + & - & 0.4 & + & + & - & - & - \\
\hline 15 & F & 19.1 & 7 & $\mathrm{Hp}$ & c.648G > T & c.648G > T & + & - & - & - & 1.3 & - & + & - & - & - \\
\hline 16 & M & 18.7 & 6.1 & $\mathrm{Hp}$ & c.648G > T & c. $648 \mathrm{G}>\mathrm{T}$ & + & - & - & + & -2.3 & + & + & - & - & - \\
\hline 17 & $F$ & 18.4 & 2 & $\mathrm{Hp}$ & c.648G > T & c.648G > T & + & - & - & - & 0.4 & - & - & - & - & - \\
\hline 18 & M & 18 & 13 & $\mathrm{Hp}$ & c. $648 \mathrm{G}>\mathrm{T}$ & c. $648 \mathrm{G}>\mathrm{T}$ & + & - & - & - & -5.1 & - & - & - & - & - \\
\hline 19 & M & 17.1 & 3 & $\mathrm{Hp}$ & c.648G > T & c.648G > T & + & + & - & + & -3.9 & - & - & - & - & - \\
\hline 20 & M & 33.3 & 8 & $\mathrm{Hp}, \mathrm{HM}$ & c. $648 \mathrm{G}>\mathrm{T}$ & p.G122D & + & + & + & - & -1.8 & + & + & + & - & - \\
\hline $21^{e}$ & F & 27.5 & 20.3 & $\mathrm{Hp}, \mathrm{HM}$ & c. $648 \mathrm{G}>\mathrm{T}$ & p.G122D & + & + & - & + & 0.4 & - & - & - & - & + \\
\hline $22^{e}$ & M & 22.8 & 16 & FS & c.648G > T & p.G122D & + & - & + & - & -0.4 & - & - & - & - & - \\
\hline 23 & M & 24.1 & 2.1 & $\mathrm{Hp}$ & c.648G > T & p.G222R & + & - & - & - & -2.2 & + & + & - & - & - \\
\hline 24 & M & 19.5 & 2.5 & $\mathrm{Hp}$ & c. $648 \mathrm{G}>\mathrm{T}$ & p.G222R & + & + & - & + & -0.9 & - & - & - & - & - \\
\hline 25 & F & 30 & 17 & $\mathrm{Hp}$ & c.648G > T & p.S326P & + & + & + & + & -1.7 & + & + & - & + & - \\
\hline 26 & $\mathrm{~F}$ & 17 & 4.3 & $\mathrm{Hp}$ & c. $648 \mathrm{G}>\mathrm{T}$ & p.F51s & + & - & - & - & -0.8 & - & - & - & - & - \\
\hline
\end{tabular}

${ }^{\mathrm{a}-\mathrm{e}}$ Siblings are indicated by identical superscript letters

$D L$ dyslipidemia, HA hepatic adenoma, OP osteoporosis, $R C$ renal complication, $S S$ short stature, SDS standard deviation score, $A N$ anemia, $D P$ delayed puberty, $G T$ gout, $P H$ pulmonary hypertension, HCC hepatocellular carcinoma, Hp hepatomegaly, GR growth retardation, FS familial screening, Ds dyspnea, HM hepatic mass, Ex expired

fibrates or 3-hydroxy-3-methyl-glutaryl-CoA reductase inhibitors for persistent dyslipidemia, despite diet therapy. Nine patients were receiving supplementation of iron because of iron-deficient anemia. Four patients started an angiotensin-converting enzyme inhibitor or an angiotensin receptor blocker for microalbuminuria and hypertension. Bisphosphonate was needed in three adult patients showing severe osteoporosis. After diet control, the biochemical analysis showed that serum glucose $(86 \pm 20.4 \mathrm{mg} / \mathrm{dL})$, lactic acid $(8.2 \pm 13.5 \mathrm{mmol} / \mathrm{L})$, and uric acid $(6.3 \pm 1.8 \mathrm{mg} / \mathrm{dL})$ levels had improved significantly $(p<0.05)$; however, when microalbuminuria and hepatic adenoma occurred in patients, improvements in these complications were not observed. When we compared the height SDS at the latest evaluation between the early diagnosed group and delayed diagnosed group, the early diagnosed patients were taller than the delayed diagnosed patients $(-1.6 \pm 0.9$ SDS vs. $-2.3 \pm 1.9$ SDS, $p<0.05)$.

\section{Molecular analysis}

Mutation analysis of the G6PC gene was conducted in all patients. Seven patients were identified by familial screening. The c.648G $>\mathrm{T}$ mutation was most frequently identified, in 81 out of 94 alleles (86.2\%; Table 1 and Fig. 1). p.G122D, p.G222R, and p.Y128* were detected in four (4.3\%), three $(3.2 \%)$, and two (2.1\%) alleles, respectively. Each of p.F51S, p.R83H, p.T255A, and p.S326P was identified in one allele (1.0\%). All eight mutations spanned all exons, except exon 4, and five mutations (62.5\%) were identified in exon 5 (Fig. 1). All patients had c.648G > T in at least one allele, and homozygous forms were 

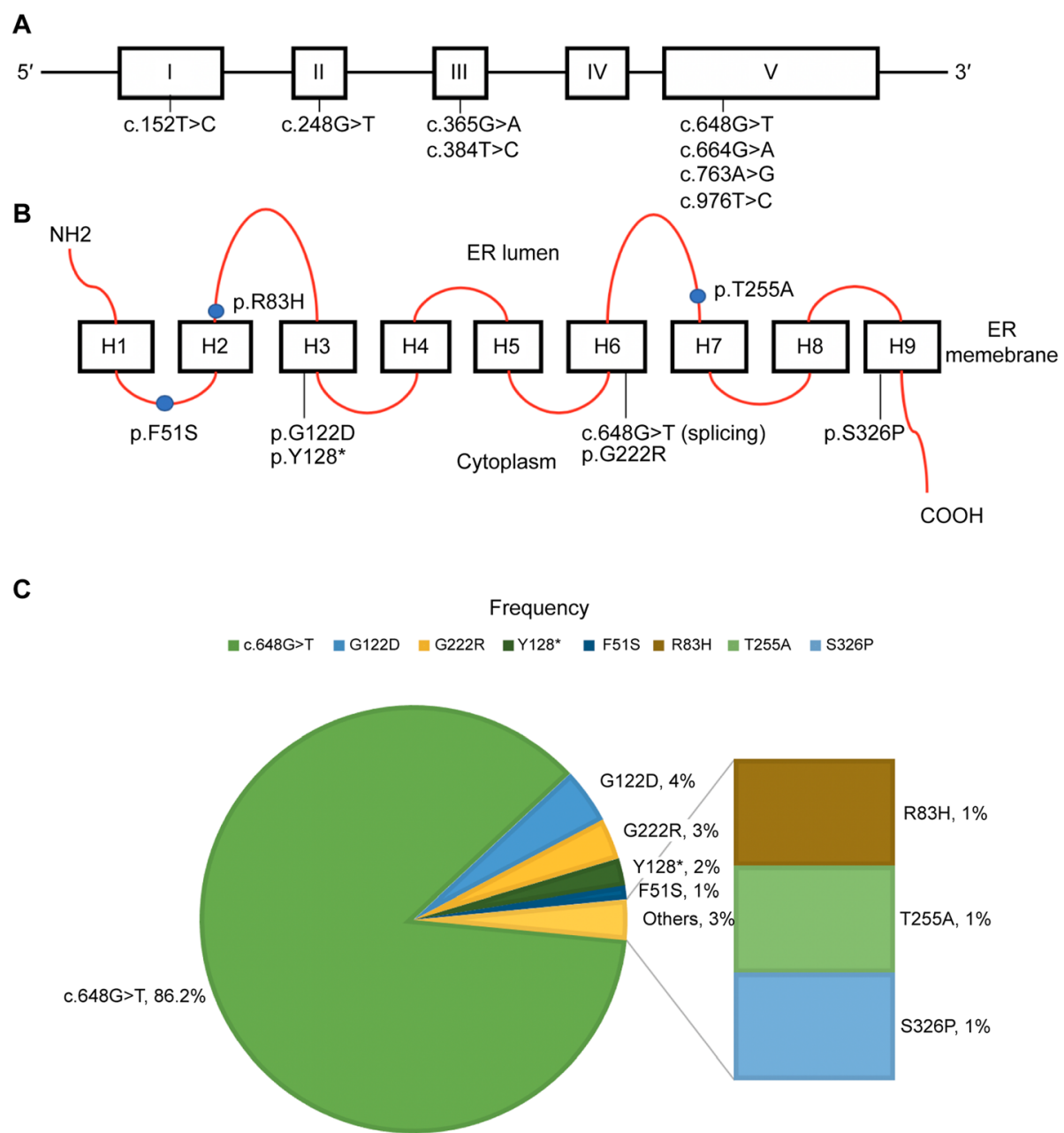

Fig. 1 Distribution and frequencies of mutations in the exons and functional domains of G6PC. a Eight mutations were identified in exons 1 through 5 of the G6PC gene, affecting the function of the encoded enzyme (b). c Frequencies of various G6PC mutations in Korean patients with GSD la, showing the predominance of the c.648G > T mutation

prevalent in our cohort $(72.3 \%$ or $34 / 47$ unrelated families). A total of 39 patients were homozygous, and 15 patients were heterozygous for c.648G > T. Comparison between the two groups showed that the homozygous patients were diagnosed later $(9.9 \pm$ 11.8 years) than were the patients heterozygous for c.648G > T $(6.7 \pm 6.9$ years; $p<0.05)$. There were no significant differences in biochemical (hemoglobin, lactic acid, triglycerides, glucose, and uric acid) and auxological (height, weight, and body mass index SDSs) findings between the two groups.

\section{Late complications in GSD la}

Among 26 adult patients, 15 males and 11 females, 14 patients $(54 \%)$ were diagnosed at an age of more than 13 years old (Table 2). The frequencies of late complications are summarized in Table 3. Fourteen patients had hepatic adenomas, and the onset age was $19.2 \pm 4.4$ years (range: 13-27 years). Among them, two patients $(14.3 \%, 2 / 14$ patients with hepatic adenomas) were diagnosed with HCC. Hepatic adenomas were first detected in these two patients at the age of 20 years (subject 2) and 27 years (subject 21). The period between hepatic adenoma and HCC diagnoses was 2 years in subject 2 and 17 years in subject 21 . Subject 2, who presented with a large, 13-cm hepatic mass, received right lobectomy, which revealed hepatic cell carcinoma, while subject 21 was lost to follow-up after the HCC diagnosis. Their blood $\alpha$ fetoprotein $(\alpha F P)$ and chorionic embryonic antigen (CEA) levels were not elevated. The pathologic findings in subject 2 showed Edmondson-Steiner grade 1 and significant disruption of the reticulin framework, supporting the diagnosis of well-differentiated HCC. 
Thirteen patients showed renal complications, and the onset age was $23.8 \pm 8.5$ years (range: $14-37$ years). The renal manifestations were microalbuminuria or proteinuria $(46.2 \%$; 6/13 patients), micro- or gross hematuria $(3 / 13 ; 23 \%)$, a renal cyst $(2 / 13 ; 15.4 \%)$, medullary calcinosis or ureter stones $(3 / 13 ; 23 \%)$, and renal insufficiency $(3 / 13 ; 23 \%)$. Subject 6 , homozygous for c.648G > T, was diagnosed at 34 years of age and presented with gout and stage 4 chronic renal disease at diagnosis (glomerular filtration rate: $18 \mathrm{~mL} / \mathrm{min} /$ $1.73 \mathrm{~m}^{2}$ ). She finally needed hemodialysis, owing to severe hyperkalemia 6 months after the GSD Ia diagnosis. Although this subject had multiple hepatic adenomas, gout, a small height (SDS: - 3.4), and osteoporosis, her older sister (subject 5), who was diagnosed by familial screening, had a normal height (SDS: 0.8), normal renal function, and a mild fatty liver, without hepatic adenomas (Table 2).

Eleven patients (six males and five females) experienced delayed puberty, with the mean age at menarche of $16.9 \pm 2.0$ years in the females. Seven patients $(27 \%)$ showed progressive gout, despite allopurinol treatment and diet therapy. Twelve patients (46\%) had osteopenia or osteoporosis, as determined by bone densitometry (mean Z-score: $-2.7 \pm 0.8$ ), and one patient (subject 1 ) experienced long-bone fractures twice.

Two patients (subjects 4 and 25) were diagnosed with pulmonary hypertension at the ages of 27 and 22 years, respectively. Subject 4 was treated with beraprost sodium, but he expired at the age of 41 years. Subject 25 had renal failure and was also treated with sildenafil citrate for pulmonary hypertension. Her initial echocardiography showed a pulmonary artery pressure of $81 \mathrm{mmHg}$ and a D-shaped ventricle; the follow-up echocardiography after sildenafil administration

Table 3 Frequencies of late complications in adult Korean patients with GSD la

\begin{tabular}{ll}
\hline Total patients $(n=26)^{\mathrm{a}}$ & $\mathrm{n}(\%)$ \\
\hline Hepatomegaly & $26(100 \%)$ \\
Dyslipidemia & $26(100 \%)$ \\
Hepatic adenoma & $14(54 \%)$ \\
Renal complication & $13(50 \%)$ \\
Osteopenia or fracture & $12(46 \%)$ \\
Short stature (SDS: $<-2.0)$ & $12(46 \%)$ \\
Anemia & $12(46 \%)$ \\
Delayed puberty & $11(42 \%)$ \\
Gout & $7(27 \%)$ \\
Pulmonary hypertension & $2(8 \%)$ \\
Hepatocellular carcinoma & $2(8 \%)$ \\
\hline
\end{tabular}

a 15 males and 11 females SDS, standard deviation score demonstrated a mild decrease in the pulmonary artery pressure, to $64 \mathrm{mmHg}$.

Growth retardation was prominent in the adult male patients; the male patients who had reached adult height had a significantly lower height SDS (SDS: $-3.9 \pm 1.8$ ) at diagnosis than female patients (SDS: $-1.7 \pm 1.8$ ). Their final height was $157.9 \pm 8.9 \mathrm{~cm}$ (SDS: $-3.1 \pm 1.8$ ) in the males and $157.8 \pm 6.8 \mathrm{~cm}$ (SDS: $-0.6 \pm 1.4$ ) in the females. This might be due to the more delayed diagnosis in males $(16.4 \pm 10.9$ years $)$ compared to females $(15.0 \pm$ 13.1 years), although this did not reach statistical significance.

\section{Discussion}

A splice mutation in exon 5 (c.648G > T) of the G6PC gene was first reported in 1995, based on the cDNA sequence from the liver of a Japanese patient with GSD Ia, and the activity of this splicing mutant was $18 \%$ of the control [10]. Our study demonstrated that c.648G > $\mathrm{T}$ was the most common mutation (81/94 alleles; $86.2 \%)$ in Korean patients with GSD Ia, which was similar to its frequency in a Japanese patient cohort $(88 / 102$ alleles; 86.4\%) and different from that in a Chinese population (36\%) $[4,11,12]$. A previous report on 13 Korean GSD Ia patients also showed that all individuals carried a c.648G $>\mathrm{T}$ mutation as a homozygous or compound heterozygous state except one patient who was a compound heterozygote for the p.G122D and p.Y128* mutations [9]. All adult patients carrying c.648G > $\mathrm{T}$ in our study showed a high prevalence of hepatic adenomas. The prevalence of G6PC mutations is different depending on the ethnicity. Thus, p. $\mathrm{R} 83 \mathrm{H}$ is prevalent in Chinese patients, p.R83C is prevalent in Jewish and eastern European patients, p.Q347* is prevalent in western Europeans, and c.459insTA is prevalent in Mexican and Central American patients [4, 13-15]. Patients carrying c.648G > T, which is prevalent in Japanese and Korean patients, tend to show mild hypoglycemia but are at a high risk for hepatic carcinoma, suggesting that mild hypoglycemia may lead to later diagnosis, poor compliance with diet therapy, and poor metabolic control in GSD Ia $[15,16]$. In this study, the homozygous patients were diagnosed later than the heterozygous patients, despite no significant differences in glucose levels (mainly postprandial) at diagnosis. Apart from glucose levels, their biochemical profiles showed elevated serum uric acid, lactic acid, and triglyceride levels at the time of diagnosis. These factors may increase the risk of late complications of GSD in patients with c.648G > T. Nine patients were diagnosed at an age of older than 20 years, of which eight patients were homozygous for c.648G $>\mathrm{T}$. These patients did not experience any severe symptoms of hypoglycemia during infancy and childhood so that 
severe late complications were their initial manifestations, including a hepatic mass, gout, osteoporosis, and pulmonary hypertension. Since growth retardation was not prominent in patients diagnosed at less than 3 years of age, this also led to late diagnosis in this cohort.

A recent study of Japanese GSD Ia patients with the c.648G > T mutation from 1999 to 2009 showed late diagnosis in male patients who presented with symptoms at the ages of 11 and 9 years, respectively, and one of the 14 patients with hepatic adenoma eventually developed HCC [8]. In addition, there have been more publications about adult GSD Ia patients diagnosed at over 30 years of age [17-19]. They were of diverse heights (-3.2 0.3 SDS) and presented with late complications including liver mass, $\mathrm{HCC}$, or renal failure rather than hypoglycemia.

There are well-established guidelines for regular surveillance of late complications during childhood to adolescence, but it is also important to perform baseline screening for these complications in all patients diagnosed during adulthood [20,21]. Late complications of GSD1a patients can be reduced by maintaining normoglycemia, which can stabilize metabolism and reduce the synthesis of glucose 6-phosphate, as well as the catabolic status [22]. Diet control improved the biochemical findings in our GSD Ia patients, but it had limited effect on late complications. The height SDS at the latest evaluation can be a predictor of therapeutic effect and compliance with therapy. This data suggested that both adherence to diet control and early diagnosis are critical for adult height outcome.

Chronic lactic acidosis, hyperuricemia, and dyslipidemia are well-known contributing factors to renal insufficiency in GSD Ia, and therefore, patients showing poor compliance with the diet should be closely monitored for microalbuminuria through regular check-ups [23, 24]. Early detection of microalbuminuria and treatment with angiotensin-converting enzyme inhibitors can delay renal deterioration.

Most hepatic adenomas are benign masses, and their size can be reduced through appropriate dietary interventions $[20,21]$. However, approximately $10 \%$ of hepatic adenomas are known to progress to HCC, and tumor markers, including $\alpha \mathrm{FP}$ and CEA, can be negative in these patients with $\operatorname{HCC}[21,25]$. Therefore, regular radiologic follow-ups in patients with hepatic adenomas are considered the main tool for early detection of HCC [26]. The pathogenesis of HCC in GSD I is not well known. Chronic hypoglycemia-induced hormonal stimulation and accumulation of metabolites in hepatocytes may be underlying factors for malignant transformation of hepatic cells [27]. Recently, an association of a CTNNB1 mutation with transformation of hepatic adenomas to $\mathrm{HCC}$ has been reported in patients with GSD I, indicating potential involvement of a modifying gene [18].

Pulmonary hypertension is a rare but fatal complication in GSD Ia, and its mechanism in GSD I has not been elucidated yet. In our cohort, two latediagnosed patients showed pulmonary hypertension in their 20s. A regular echocardiography should be performed in adult patients with GSD Ia, and sildenafil, a phosphodiesterase- 5 inhibitor, seems to be effective in GSD patients with pulmonary hypertension [28].

Considering the poor prognosis of patients who are diagnosed with GSD Ia at an age older than 20 years, a clinician should not only suspect GSD in patients who present with common endocrine and metabolic issues, including dyslipidemia, hyperuricemia, and osteopenia, but also do familial screening. For stabilizing the metabolic status in patients with GSD I, a continuous glucose monitoring system is considered a useful tool to avoid a hypoglycemic event, which occurs at a serum glucose level of less than $70 \mathrm{mg} / \mathrm{dL}$ and triggers a counterregulatory hormone response, leading to lactic acidosis and synthesis of uric acids and free fatty acids in patients with GSD [29].

Since mild hypoglycemia in patients with GSD Ia does not always guarantee a favorable long-term prognosis, an early diagnosis, even in patients with mild symptoms, is needed to prevent severe complications. Recently, newborn screening has been expanded to include lysosomal storage disorders such as Gaucher disease, Pompe disease, and Fabry disease, as well as mucopolysaccharidosis type I and Niemann-Pick types A/B disease, for early diagnosis and treatment [30]. Considering its irreversible progressive complications, potential treatability with proper management, and genetic background in Korea, GSD Ia can be a candidate for newborn screening in the future. Indeed, neonatal genetic screening for the c.648G > T mutation in the G6PC gene may help with early diagnosis in Korean and Japanese populations, although genetic heterogeneity can bring concerns about genetic counseling and unnecessary evaluation [31]. Recently, adeno-associated virus vector-treated GSD Ia in mice showed a possibility to prevent the development of hepatocellular adenoma/carcinoma [32, 33], but was not able to abolish the tumor. Interestingly, Cho et al. [33] demonstrated lower glucose 6-phosphatase expression in Hepatic adenoma and HCC compared to that in nontumor tissue in a G6PC-knockout mouse after gene therapy despite a similar copy number for the vector genome, and they suggested that the downregulation of glucocorticoid signaling in tumor tissue inhibits gene therapy expression and tumor abrogation. Therefore, it may be difficult to treat late complications through gene therapy alone. However, a new therapeutic strategy targeting the upregulation of glucocorticoid signaling might 
function in combination with gene therapy for patients with hepatic adenomas or HCC.

Although hepatocyte-targeted gene therapy using an adeno-associated virus vector is in a clinical trial for adult patients with GSD Ia (NCT03517085, NCT03970278; http://www.clinicaltrials.gov), there are many concerning issues and hurdles to overcome. Since the c.648G > T mutation generates aberrant splicing at the transcription level, correction of altered splicing will be possible using antisense oligonucleotide therapy. This genotype-based therapy will be beneficial for more than $80 \%$ of patients with GSD Ia in Korea and Japan.

This study entails several limitations. First, this was a retrospective observational study, making statistical analysis problematic because of many uncontrolled confounding factors. Second, biochemical analysis of G6PC was not conducted, making it impossible to correlate biochemical data with the genotype.

\section{Conclusions}

In conclusion, our study showed a prevalent mutation, c.648G > T, in the G6PC gene in Korean patients with GSD Ia, and adult patients showed diverse and serious complications, despite mild hypoglycemia and improvement in their biochemical test results. Late diagnosis and overlooked mild hypoglycemia may lead to poor outcomes in Korean patients with GSD. Early detection and proper control of the glucose status in patients with GSD Ia are necessary for a favorable long-term prognosis.

\section{Methods}

\section{Patients and clinical assessment}

A total of 54 patients (33 males and 21 females) from 47 unrelated families, who were diagnosed with GSD Ia between 1999 and 2017, were included in this study (Table 1). Electronic charts were reviewed retrospectively for clinical features, biochemical test results, molecular genetic testing, medications, long-term outcomes, and treatments. Serum glucose, uric acid, lactate, cholesterol, triglycerides, aspartate aminotransferase, alanine aminotransaminase, blood gas, and hemoglobin were monitored to assess the metabolic status. The height, weight, head circumference, and body mass index were tracked to assess growth, and height SDSs were calculated based on the Korean standards for height. Delayed puberty was defined as no secondary sexual manifestations appearing until the age of 14 years for males and 13 years for females. Regular abdominal ultrasound was performed to detect hepatic adenomas. Blood $\alpha F P$ and CEA levels and liver MRI or CT were used when hepatic cell carcinoma was suspected. Bone density tests included DEXA scans and measurement of $25-\mathrm{OH}$ vitamin D levels, and osteopenia and osteoporosis were defined as Z-scores $<-2.0$ and $<-2.5$, respectively. The DEXA scans were not corrected by bone age or stature. Renal complications were assessed based on the glomerular filtration rate, spot urine microalbumin, and/or protein-to-creatinine ratio, and kidney ultrasound was performed regularly. Pulmonary hypertension was assessed by periodic echocardiography and electrocardiogram.

\section{Molecular analysis}

All mutation analyses of the G6PC gene were performed through Sanger sequencing at the Asan Medical Center (Seoul, Korea). Before genetic testing, informed consent was obtained from all patients and their parents. Genomic DNA from peripheral leukocytes was used as a template, and all five exons of the G6PC gene were amplified by PCR using intronic primers, designed by the authors, and the GoTaq ${ }^{\circ}$ colorless master mix (Promega, Madison, WI, USA). Sequencing was performed using the BigDye ${ }^{\circ}$ Terminator v3.1 cycle sequencing kit (Applied Biosystems, Foster City, CA, USA) on an ABI 3130xl genetic analyzer (Applied Biosystems).

This study was approved by the Research Ethics Board at the Asan Medical Center (approval number: S20191025-0001).

\section{Statistical analysis}

Statistical analysis was performed using SPSS for Mac OS version 24.0 (SPSS, Inc., Chicago, IL, USA). Continuous variables were analyzed using a two-sample $t$-test or Mann-Whitney $U$-test.

\section{Supplementary information}

Supplementary information accompanies this paper at https://doi.org/10. 1186/s13023-020-1321-0.

Additional file 1: Table S1. Genotype and age at diagnosis for 54 Korean patients with glycogen storage disease type la.

\section{Abbreviations \\ CEA: Chorionic embryonic antigen; G6PC: Glucose-6-phosphatase; GSD: Glycogen storage disease; HCC: Hepatocellular carcinoma; SDS: Standard deviation score; aFP: a-Fetoprotein}

\section{Acknowledgements}

We thank the patients enrolled in this study and their parents.

\section{Authors' contributions}

Y-MK contributed to data analysis and interpretation and the drafting of the paper. J-HC, B-HL, G-HK, and KMK contributed to data analysis and interpretation and critical review of the paper. Y-MK and H-WY contributed to the research design, data analysis and interpretation, the drafting and critical review of the paper, and the approval of the submitted paper. All authors have read and approved the final manuscript.

\section{Funding}

Not applicable. 


\section{Availability of data and materials}

Not applicable.

\section{Ethics approval and consent to participate}

Written informed consents were obtained from patients and the parents of each patient, and this study was approved by the Research Ethics Board at the Asan Medical Center (approval number: S2019-1025-0001).

\section{Consent for publication}

Not applicable.

\section{Competing interests}

The authors declare that they have no competing interests.

\section{Author details}

'Department of Pediatrics, Chungnam National University Hospital, Chungnam National University, College of Medicine, Daejeon, Korea. ${ }^{2}$ Department of Pediatrics, Asan Medical Center Children's Hospital, University of Ulsan, College of Medicine, Seoul, Korea. ${ }^{3}$ Department of Medical Genetics, Asan Medical Center Children's Hospital, University of Ulsan, College of Medicine, Seoul, Korea.

Received: 5 November 2019 Accepted: 28 January 2020

Published online: 11 February 2020

\section{References}

1. Froissart R, Piraud M, Boudjemline AM, Vianey-Saban C, Petit F, HubertBuron A, et al. Glucose-6-phosphatase deficiency. Orphanet J Rare Dis. 2011; $6: 27$.

2. Hicks J, Wartchow E, Mierau G. Glycogen storage diseases: a brief review and update on clinical features, genetic abnormalities, pathologic features, and treatment. Ultrastruct Pathol. 2011:35(5):183-96.

3. Lei KJ, Chen H, Pan CJ, Ward JM, Mosinger B Jr, Lee EJ, et al. Glucose-6phosphatase dependent substrate transport in the glycogen storage disease type-1a mouse. Nat Genet. 1996;13(2):203-9.

4. Chou JY, Matern D, Mansfield BC, Chen YT. Type I glycogen storage diseases: disorders of the glucose-6-phosphatase complex. Curr Mol Med. 2002:2(2):121-43.

5. Moses SW. Historical highlights and unsolved problems in glycogen storage disease type 1. Eur J Pediatr. 2002;161(Suppl 1):S2-9.

6. Talente GM, Coleman RA, Alter C, Baker L, Brown BI, Cannon RA, et al. Glycogen storage disease in adults. Ann Intern Med. 1994;120(3):218-26.

7. Lei KJ, Shelly LL, Pan CJ, Sidbury JB, Chou JY. Mutations in the glucose-6phosphatase gene that cause glycogen storage disease type 1a. Science. 1993:262(5133):580-3.

8. Kido J, Nakamura K, Matsumoto S, Mitsubuchi H, Ohura T, Shigematsu Y, et al. Current status of hepatic glycogen storage disease in Japan: clinical manifestations, treatments and long-term outcomes. J Hum Genet. 2013; 58(5):285-92.

9. Ki CS, Han SH, Kim HJ, Lee SG, Kim EJ, Kim JW, et al. Mutation spectrum of the glucose-6-phosphatase gene and its implication in molecular diagnosis of Korean patients with glycogen storage disease type la. Clin Genet. 2004 65(6):487-9

10. Kajihara S, Matsuhashi S, Yamamoto K, Kido K, Tsuji K, Tanae A, et al. Exon redefinition by a point mutation within exon 5 of the glucose-6phosphatase gene is the major cause of glycogen storage disease type 1a in Japan. Am J Hum Genet. 1995;57(3):549-55.

11. Akanuma J, Nishigaki T, Fujii K, Matsubara Y, Inui K, Takahashi K, et al. Glycogen storage disease type la: molecular diagnosis of 51 Japanese patients and characterization of splicing mutations by analysis of ectopically transcribed mRNA from lymphoblastoid cells. Am J Med Genet. 2000;91(2): 107-12.

12. Lam CW, But WM, Shek CC, Tong SF, Chan YS, Choy KW, et al. Glucose-6phosphatase gene (727G-->T) splicing mutation is prevalent in Hong Kong Chinese patients with glycogen storage disease type 1a. Clin Genet. 1998; 53(3):184-90.

13. Rake JP, Visser G, Labrune P, Leonard JV, Ullrich K, Smit GP. Glycogen storage disease type I: diagnosis, management, clinical course and outcome. Results of the European Study on Glycogen Storage Disease Type I (ESGSD I). Eur J Pediatr. 2002;161(Suppl 1):S20-34
14. Lei KJ, Chen YT, Chen H, Wong $\sqcup$, Liu JL, McConkie-Rosell A, et al. Genetic basis of glycogen storage disease type 1a: prevalent mutations at the glucose-6-phosphatase locus. Am J Hum Genet. 1995;57(4):766-71.

15. Matern D, Seydewitz HH, Bali D, Lang C, Chen YT. Glycogen storage disease type I: diagnosis and phenotype/genotype correlation. Eur J Pediatr. 2002; 161(Suppl 1):S10-9.

16. Nakamura T, Ozawa T, Kawasaki T, Nakamura H, Sugimura H. Glucose-6phosphatase gene mutations in 20 adult Japanese patients with glycogen storage disease type 1a with reference to hepatic tumors. J Gastroenterol Hepatol. 2001;16(12):1402-8.

17. Carvalho PM, Silva NJ, Dias PG, Porto JF, Santos LC, Costa JM. Glycogen storage disease type la - a secondary cause for hyperlipidemia: report of five cases. J Diabetes Metab Disord. 2013;12(1):25.

18. Cassiman D, Libbrecht L, Verslype C, Meersseman W, Troisi R, Zucman-Rossi J, et al. An adult male patient with multiple adenomas and a hepatocellular carcinoma: mild glycogen storage disease type la. J Hepatol. 2010;53(1):213-7.

19. Shieh JJ, Lu YH, Huang SW, Huang YH, Sun CH, Chiou HJ, et al. Misdiagnosis as steatohepatitis in a family with mild glycogen storage disease type la. Gene. 2012;509(1):154-7.

20. Rake JP, Visser G, Labrune P, Leonard JV, Ullrich K, Smit GP, et al. Guidelines for management of glycogen storage disease type I - European study on glycogen storage disease type I (ESGSD I). Eur J Pediatr. 2002;161(Suppl 1):S112-9.

21. Kishnani PS, Austin SL, Abdenur JE, Arn P, Bali DS, Boney A, et al. Diagnosis and management of glycogen storage disease type I: a practice guideline of the American College of Medical Genetics and Genomics. Genet Med. 2014;16(11):e1.

22. Shah KK, O'Dell SD. Effect of dietary interventions in the maintenance of normoglycaemia in glycogen storage disease type 1a: a systematic review and meta-analysis. J Hum Nutr Diet. 2013;26(4):329-39.

23. Martens DH, Rake JP, Navis G, Fidler V, van Dael CM, Smit GP. Renal function in glycogen storage disease type I, natural course, and renopreservative effects of ACE inhibition. Clin J Am Soc Nephrol. 2009;4(11):1741-6.

24. Araoka T, Takeoka H, Abe H, Kishi S, Araki M, Nishioka K, et al. Early diagnosis and treatment may prevent the development of complications in an adult patient with glycogen storage disease type la. Intern Med. 2010; 49(16):1787-92.

25. Franco LM, Krishnamurthy $\mathrm{V}$, Bali D, Weinstein DA, Arn P, Clary B, et al. Hepatocellular carcinoma in glycogen storage disease type la: a case series. J Inherit Metab Dis. 2005:28(2):153-62

26. Sakamoto A, Hayashi H, Sakamoto I, Isomoto I, Eguchi S, Takatsuki M, et al. Multiple hepatocellular adenomas in a patient with glycogen storage disease type I: various enhancement patterns in MRI with Gd-EOB-DTPA Abdom Imaging. 2012;37(2):239-43.

27. Mikuriya $Y$, Oshita A, Tashiro $H$, Amano $H$, Kobayashi $T$, Arihiro K, et al. Hepatocellular carcinoma and focal nodular hyperplasia of the liver in a glycogen storage disease patient. World J Hepatol. 2012:4(6):191-5.

28. Ueno M, Murakami T, Takeda A, Kubota M. Efficacy of oral sildenafil in a beraprost-treated patient with severe pulmonary hypertension secondary to type I glycogen storage disease. Circ J. 2009;73(10):1965-8.

29. Herbert M, Pendyal S, Rairikar M, Halaby C, Benjamin RW, Kishnani PS. Role of continuous glucose monitoring in the management of glycogen storage disorders. J Inherit Metab Dis. 2018;41(6):917-27.

30. Schielen P, Kemper EA, Gelb MH. Newborn Screening for Lysosomal Storage Diseases: A Concise Review of the Literature on Screening Methods, Therapeutic Possibilities and Regional Programs. Int J Neonatal Screen. 2017; 3(2). https://doi.org/10.3390/ijns3020006

31. Kelly N, Makarem DC, Wasserstein MP. Screening of newborns for disorders with high benefit-risk ratios should be mandatory. J Law Med Ethics. 2016; 44(2):231-40.

32. Kim GY, Kwon JH, Cho JH, Zhang L, Mansfield BC, Chou JY. Downregulation of pathways implicated in liver inflammation and tumorigenesis of glycogen storage disease type la mice receiving gene therapy. Hum Mol Genet. 2017;26(10):1890-9.

33. Cho JH, Lee YM, Starost MF, Mansfield BC, Chou JY. Gene therapy prevents hepatic tumor initiation in murine glycogen storage disease type la at the tumor-developing stage. J Inherit Metab Dis. 2019:42(3):459-69.

\section{Publisher's Note}

Springer Nature remains neutral with regard to jurisdictional claims in published maps and institutional affiliations. 